\title{
Personal Collection in MERLOT as a Compilation of Learning Object Repository
}

\author{
Anat Cohen \\ Tel Aviv University, Tel Aviv, Israel \\ anatco@post.tau.ac.il
Sorel Reisman and Barbra Bied Sperling
California State University Office of the Chancellor, Long Beach, California, USA

sreisman@calstate.edu bsperling@calstate.edu

\begin{abstract}
This study focuses on the phenomenon of Personal Collection in a big central portal connected to multiple learning object repositories, called MERLOT. This portal contains only the object metadata and allows users access to the learning materials stored in several online repositories.

A Personal Collection is a compilation of MERLOT modules that MERLOT Members can access easily to use for specific purposes, classes or topics. Personal Collections (PCs) can promote the reuse of Open Educational Resources and enhance pedagogical content knowledge. PCs offer the stimulating possibility of personalizing public learning object repositories, with the emphasis on the individual. Even though PCs add a strong element of personalization to the system, they still retain the many institutional benefits of learning object repositories.

The objective of the study is to explore the PCs extent of use in the MERLOT repository and to understand the experience of the repository members who were first to adopt these PCs with the creation process, its design and patterns of usage, in order to expand the use of PC to other active members, along with understanding the advantages of PCs and their instructional value.
\end{abstract}

Keywords: Repositories, Open Educational Resource, Personal Collection, MERLOT.

\section{Introduction}

The current global trends of sharing and retrieving Open Educational Resources (OERs) provides a strategic opportunity to improve the quality of education as well as facilitate policy dialogue, knowledge sharing and capacity building (Downes, 2007; Bonk, 2009; Hilton et al., 2010; Hilton

Material published as part of this publication, either on-line or in print, is copyrighted by the Informing Science Institute. Permission to make digital or paper copy of part or all of these works for personal or classroom use is granted without fee provided that the copies are not made or distributed for profit or commercial advantage AND that copies 1) bear this notice in full and 2) give the full citation on the first page. It is permissible to abstract these works so long as credit is given. To copy in all other cases or to republish or to post on a server or to redistribute to lists requires specific permission and payment of a fee. Contact Publisher@InformingScience.org to request redistribution permission.
\& Wiley, 2011). However, despite the many advantages inherent in OERs the level of OER adoption into common teaching practices remains quite low (De Liddo, 2010). Furthermore, some have argued that OERs are still mainly created in the developed World (Butcher \& Hoosen, 2012).

The aim of this research is to explore the Personal Collection (PC) tool of MERLOT (www.merlot.org) as a facilitator 
for adoption of OERs into common teaching practices. A PC is a compilation of MERLOT modules that members can access easily to use for specific purposes, classes or topics. The owner of the PC can annotate each collection to easily explain its purpose, a pedagogical approach and if it relates to a specific course. PCs offer the stimulating possibility of personalizing public learning object repositories, with the emphasis on the individual. Even though PCs add a strong element of personalization to the system, they still retain the many institutional benefits of learning object repositories.

This research provides data regarding the usage rate of PCs and describes the extent of materials reused through PC and the uses and aims. These findings assist in expanding the use of PCs, along with understanding the advantages of PCs and their instructional value. Furthermore, they will help the administrator of the repository to design and plan the technological infrastructure needed to receive, store, and share the published PCs, along with adapting to other communities that are connected to MERLOT, such as the MAOR and Chile future repository.

\section{Background}

The continuous growth of learning resources available on-line (The Directory of Open Access Repositories - OpenDOAR, 2012) supports the trend of openness of materials and their availability on the web as Open Educational Resources (OER). The term open educational resource is the results of a spring 2002 meeting held at UNESCO, and organised with support of WCET and the William and Flora Hewlett Foundation (Wiley, 2007). OERs are defined as "technology-enabled, open provision of educational resources for consultation, use and adaptation by a community of users for non-commercial purposes" (UNESCO, 2002). OER refers to educational resources that are freely available over the Web or the Internet for use by educators and learners without an accompanying need to pay royalties or license fees (Butcher \& Hoosen, 2012). They are predominantly used by teachers and educational institutions to support course development, but they can also be used directly by students. OERs include learning objects such as lecture material, references and readings, simulations, experiments and demonstrations, as well as syllabi, curricula and teachers' guides. OERs are a relatively new phenomenon, which may be seen as part of a larger trend toward openness in education, including more well-known and established movements such as Open Source Software (OSS) and Open Access (OA) (Hylén, 2006).

Institutions and organizations such as MIT, Carnegie Mellon, Berkeley, Connexions Globe, The National Science Digital Library, MERLOT and others are offering a wide range of free learning materials online in different configurations, such as: free educational courses (e.g. MIT open courseware) and textbooks; repositories of learning objects (e.g. Globe and MERLOT) that manage access to reusable learning content, as it has been defined by several authors (Monge, Ovelar \& Azpeitia, 2008); open source learning management systems (e.g. Moodle) and open software tools. These are offered openly and for free, contrary to the policy that was acceptable by universities and educational institutions not long ago (Abelson, 2008; Malloy \& Hanley, 2001; Taylor, 2007). Israeli institutions (academic and content developers) follow the international trend. They are willing to contribute their learning materials and share them with their peers (Cohen, Shmueli, \& Nachmias, 2011). The Open University of Israel (OUI) is the first academic institution in Israel to join the worldwide trend toward providing access to knowledge for the public good. As part of this trend, within the framework of the Pe'er project (the Hebrew acronym for "Opening the Treasures of the Mind"), the OUI offers Hebrew readers in Israel and throughout the world free access to its most valuable assets: textbooks and study materials (The Open University of Israel, 2012).

The concept of OER has gained significant currency around the world, becoming a subject of heightened interest in policy-making and in institutional circles as many people and institutions explore its potential to contribute to improved delivery of education and its ability to tackle some 
of the key problems facing education systems (Butcher \& Hoosen, 2012). For the first time in human history we have the tools to enable everyone to attain all the education they desire (Wiley, Green, \& Soares, 2012). The current global trends of sharing and retrieving materials, through which multiple content developers offer their learning materials to the public free of charge, provide a strategic opportunity to improve the quality of education as well as facilitate policy dialogue, knowledge sharing and capacity building. OERs provide a significant opportunity to share both content knowledge and pedagogical practice. However, Hilton, Wiley, Stein \& Johnson (2010) claim that "it is important to recognize that 'openness' is not a dichotomous concept; rather, there is a continuum of openness. Designers of OER should decide early on whether they wish to facilitate reuse and redistribution only, or if they also want enable revising and remixing. Those who wish to facilitate reuse and remix of OER should license their works accordingly".

\section{MERLOT}

MERLOT is a free and open online community of resources designed primarily for faculty, staff and students of higher education from around the world to share their learning materials and pedagogy. MERLOT is a leading edge, user-centered, collection of peer reviewed higher education, online learning materials, catalogued by registered members and a set of faculty development support services. MERLOT's strategic goal is to improve the effectiveness of teaching and learning by increasing the quantity and quality of peer reviewed online learning materials that can be easily incorporated into faculty designed courses. MERLOT's activities are based on the creative collaboration and support of its Individual Members, Institutional Partners, Corporate Partners and Editorial Boards (MERLOT, 2012).

MERLOT is a major portal that is connected to multiple digital learning object repositories. Learning objects are elements of a new type of computer-based instruction grounded in the object-oriented paradigm of computer science that can be reused a number of times (Dahl \& Nygaard, 1966; Friesen, 2009) in multiple contexts. Digital repositories are systems that enable the storage, discovery, and retrieval of meta-data and/or electronic learning objects stored at a local or distributed level (The JORUM Team, 2006).

MERLOT (Malloy \& Hanley, 2001) contains only the object meta-data and allows access to learning materials hosted in the connected repositories. The objects stored in these repositories are characterized according to international standards for learning objects meta-data (LOM). The meta-data fields describe the object and the possibilities for its use, so that objects may be located using keywords, retrieved, and examined to see whether they suit learners' needs (Cohen, Shmueli, \& Nachmias, 2011). The MERLOT repository not only provides access to learning materials, but to learning exercises, comments, personal collections and Content Builder web pages, all designed to enhance the teaching experience of an online learning material. The learning materials are categorized into 18 different learning material types. A large selection of materials in MERLOT also has assignments and comments attached to them. It is additionally possible to add any material to a personal collection, which helps in organizing your teaching materials for each of your courses.

\section{Personal Collection in MERLOT}

Learning object repositories are a shared, open and public space. However, the possibility and ability of personal expression in an open, global public space is crucial. Personal spaces allow users to construct, preserve and present knowledge in a way uniquely suited to their individual patterns of use by utilizing technological tools to mark materials such as tags, bookmarks, personal collections, etc. (Razavi \& Iverson, 2006; Cechinel, Sánchez-Alonso, \& GarcíaBarriocanal, 2011; Qian, 2010). Alongside the many advantages inherent in sharing and integrating materials in a public space, personal spaces are still supported, which allow users self expres- 
sion within the learning and creative process. Personal workspaces within open repositories allow the construction of a unique learning process in private spaces that suit the learner's needs. Creators of these learning processes can use materials developed by others and include them in their personal spaces within the repository. At the same time they may transfer learning materials from their personal spaces and into the public space and thus share them with others. It is the decision of the creators whether to make personal use of the new processes, or to distribute them to other users. The building blocks - the learning objects - remain in the public domain, yet the construction of the new process takes place in a personal space.

Personal Collections in MERLOT help personalize the MERLOT collection for Members. A Personal Collection (PC)is a compilation of MERLOT modules that MERLOT Members can access easily to use for specific purposes, classes or topics. The owner of the PC can annotate each collection to more easily explain the purpose of it.

Despite the many advantages inherent in OERs (Downes, 2007) and learning object repositories, the usage of these open learning materials is rather low. Furthermore, an important element of OERs is the permission to use the materials in new ways, including revising and remixing them. However, the revision and remix rates for OERs are relatively low (Hilton, Lutz, \& Wiley, 2012) and not always encouraged by the institution, both within higher education institutions and other informal educational systems. The aim of this research is to explore the PC tool of MERLOT (www.merlot.org) as a facilitator for adoption of OERs into common teaching practices.

\section{Methodology}

This study investigates the phenomenon of PC in MERLOT - a big central portal connected to multiple learning object repositories.

\section{Research Aims and Questions}

The aim of this research is to explore the PC tool of MERLOT (www.merlot.org) as a facilitator for adoption of OERs into common teaching practices. The characteristics of PCs and their use are examined in order to understand how they can promote the use of repositories, enhance pedagogical content knowledge and engage the repository members. In order to provide a wide view of the PC process in MERLOT and benefits to the repository users, this study will measure the usage rate of PCs and the extent of use and aims of users, as an initial step toward understanding the experience of the repository members who were first to adopt these PCs (early adopter group). Correspondingly, this study provides answers to three main questions: (a) What is the extent of PC use; (b) To what extent were materials retrieved/ reused through Personal Collections?; and (c) What are the PC uses and aims?

\section{Research Field}

The study was initially conducted on the PCs which were cataloged in the MERLOT portal as of June 2012 ( $N=20,816$ PCs). Subsequently, the study focuses on the 9,841 contributors to these PCs.

\section{Method}

The MERLOT repository automatically accumulates a vast amount of data in its server Web-logs. Through web mining techniques, access to the server database was enabled and data regarding the PCs, that were cataloged in the MERLOT repository, was retrieved. The data regarding the PCs was extracted directly from the server Web-logs and was organized in various tables that provide data regarding the PC description, pattern of usage, and PCs contributors. For example, the PCs information table provides data regarding the PC ID, title, description (including use and aim), 
date created/ modified, number of materials, creator ID and name; and the $P C$ creators information table provides data regarding the member ID (the creator), affiliation, discipline, member type, contribution level, number of PCs created, number of authored materials, number of peer reviews and comments, etc. The data are extracted from the Web-logs and provide crucial information regarding the PCs.

\section{Findings}

This section provides data regarding the usage rate of PCs and describes the extent of their use and aims, as an initial step toward understanding the experience of the repository members who were first to adopt these PCs (early adopter group).

\section{The Usage Rate of Personal Collections}

MERLOT has 104,771 members (as of June 14, 2012). Of those, 9,841 members have 2 PCs on average $(\mathrm{StD}=3.7)$, and there are a total of 20,816 Private Collections among the following nine disciplines: Arts (956); Business (1,563); Education (3,879); Humanities (3,099); Mathematics and Statistics (989); Science and Technology $(5,697)$; Social Sciences $(1,152)$; Workforce Development (91); and Academic Support Services $(2,059)$. All PCs are shared with the community.

The number of PCs grows over time as well as the number of members creating the PCs (Figure 1). During the past six years, the number of PCs increased from 7,837 to 20,816 , and the number of PC creators increased, as well, from 4,330 to 9,841 .

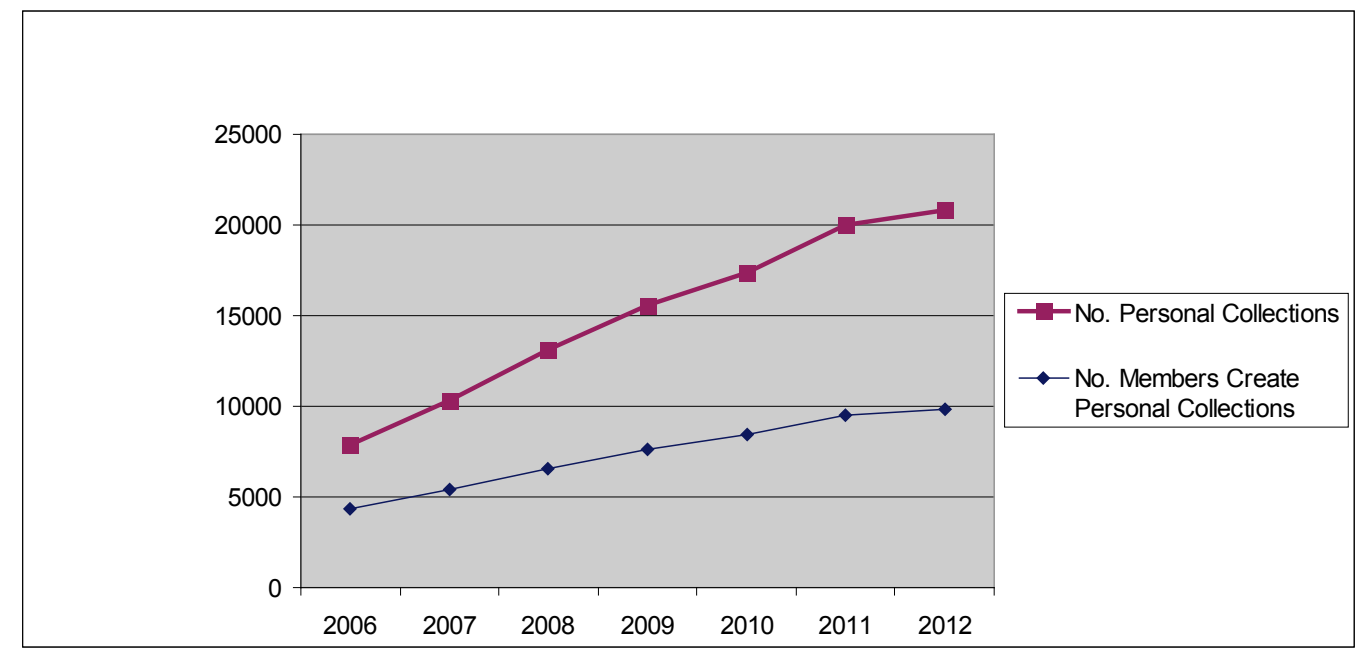

Figure 1: Growth rate of Personal Collections and their creators

The affiliation of most of the PC Creators is education (57.7\%); other affiliations are non-profit organizations, corporations and governments. Most of the PC Creators are faculty members $(4,603 ; 47 \%)$ and students $(2,992 ; 30.5 \%)$; others are staff members, $k-12$ teachers, librarians and content developers.

$\mathrm{PC}$ has been found to be the most widely used component in MERLOT. More than half $(9,841$; $61 \%$ ) of all 16,134 members that contributed at least one item to the MERLOT repository, created PCs. Furthermore, the number of PC Creators $(\mathrm{N}=9,841)$ was greater than any other contributor type, such as: Comment Writers, Authors of Materials, Peer Reviewers, Learning Exercise Submitters, and Content Builder Material Submitters.

Many of the PC Creators are active users in MERLOT. Of the 9,841 that created PCs, 1,478 members have also contributed materials and peer reviews to the repository, as well as written 
comments. It was further found that $95 \%$ of the PC Creators have contributed between 1-10 items to the repository (including their collections).

\section{Materials Retrieve/ Reuse through PCs}

The MERLOT repository provides access to 35,186 educational materials in varied disciplines and types. Of those, $33.4 \%(\mathrm{~N}=11,390)$ were reused and integrated in the 20,816 PCs. Due to the fact that material can be integrated in more than one PC, a total of 51,164 links to materials were found in all 20,816 PCs. Figure 2 presents the distribution of the materials in PCs. PCs differ in the number of items in them. There are a significant number of PCs which do not include links to materials while others do include links to different materials. The highest number of materials in the PCs was found to be 185. In Figure 2 a logarithmic scale (base 10) is presented on the $y$-axis, since the range of values that was found regarding the number of the PCs was very large. The smallest value for the number of PCs is 1, while the largest is 9447 . The logarithmic scale enables us to display the dispersion of the lower values. The materials in PCs represent a variety of disciplines (Science and Technology, Humanities, Business, Education, Social Sciences, Arts, Mathematics and Statistics, Workforce Development, and Academic Support Services) and types (Reference Material, Tutorial, Presentation, Simulation, Collection, Animation, Drill and Practice, Open Textbook, Open Journal-Article, Online Course, Quiz/Test, Case Study, Assessment Tool, Assignment, Learning Object Repository, Workshop and Training Material, Social Networking Tool, Development Tool, and ePortfolio).

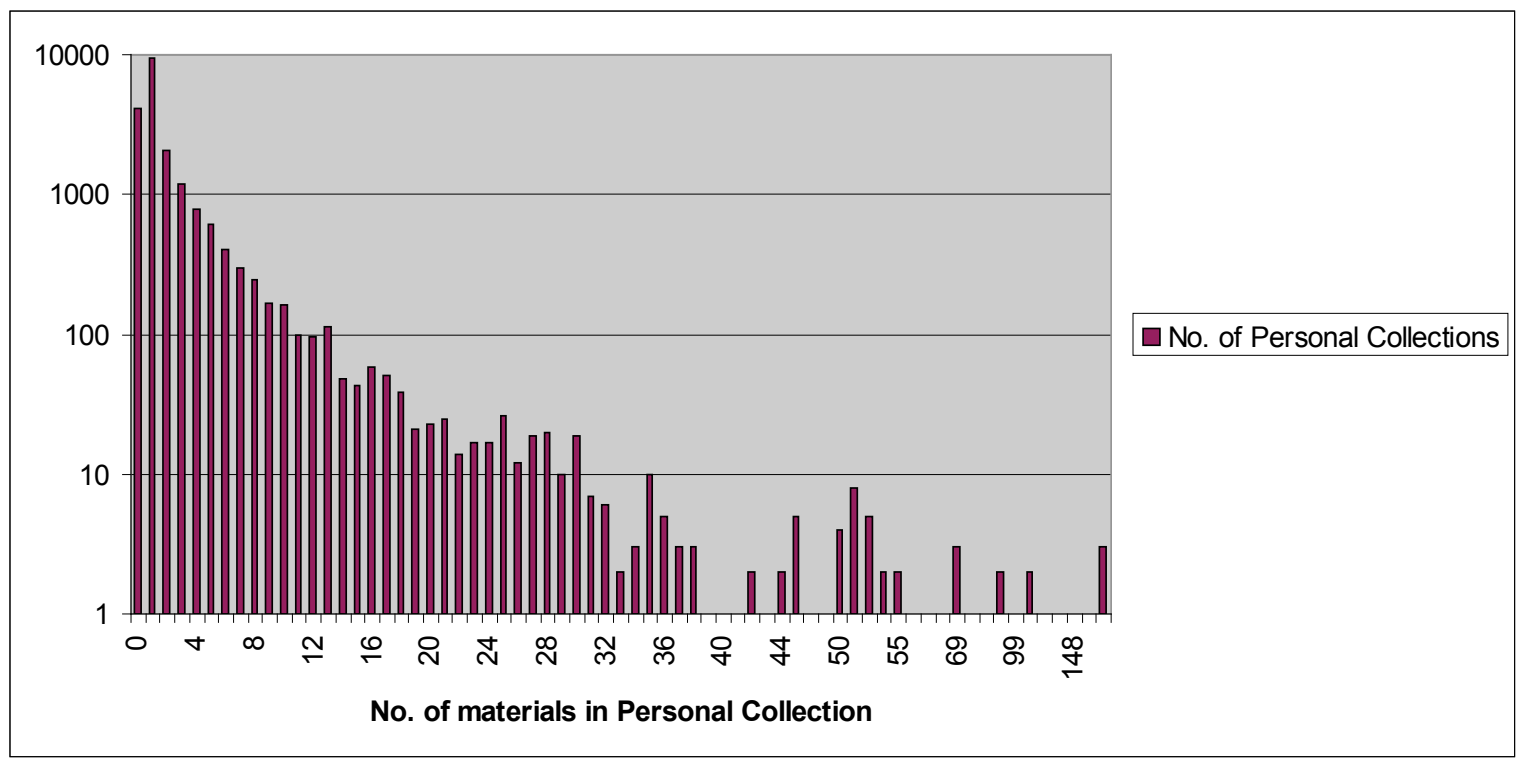

Figure 2: No. of materials in Personal Collections

PCs offer the stimulating possibility of personalizing public learning object repositories, with the emphasis on the individual. Even though PCs add a strong element of personalization to the system, they still retain the many institutional benefits of learning object repositories. Furthermore, the number of times that each learning object appears in PCs has been demonstrated to be highly correlated with quality, since it is positively associated with good materials for every discipline category (Cechinel et al., 2011).

\section{Personal Collection Uses and Aims}

The findings show that PCs are applicable for a variety of uses. In this section various common usages will be presented. 
MERLOT members create PCs for various uses with diverse goals: for their own use (e.g. my tools, my resources), while allowing others to view and copy; for other users, such as the students in their courses and other students; for teachers of their discipline; for their professional community, etc.

The most common usage was a PC as an assemblage of resources and tools, which support the learning of particular domain skills and their improvement. It is used for rapid detection of these resources and tools at any time and for repeated use in the process of teaching or learning. In these PCs, new teaching and learning processes are constructed on the basis of the existing materials that are available. The creator uses materials (learning objects) which are developed by others and includes them in his personal space within the repository. The materials - the learning objects - remain in the public domain, yet the construction of the new process takes place in a personal space. PCs also were found commonly as an assemblage of support materials for a course, or as one wrote "Non-text teaching materials - some interactive and possibly relevant resources". To these materials the user added meta-data to describe the resource. For example: "This is an excellent interactive on-line case study of the Cameron Hot Air Balloon factory in Bristol, UK. It covers many aspects of the functional disciplines of business: human resource management, operations, production management, accounting, marketing, etc. It also includes hypertext links to different departments in the ACTUAL FACTORY! The site is illustrated with real photos, bios of various managers, and data. This is a real find!" (The Cameron Balloon Factory, Author: University of Bristol, BizEd, Submitter: Ron Purser).

Another common usage was a PC as a stage (environment) for the presentation of resources and various outcomes for the community. For example, displaying student products or project products, whether they manage and operate them or whether these projects are gathered from the repositories. One example is the Teaching Resources for Ecuador and Peru "In 2008 the Center for Latin American Studies was awarded Fulbright Hays Group Project Abroad funding to take twelve K-12 teachers to Ecuador and Peru for four weeks. During that time teachers attended seminars, met with local indigenous communities, and visited a variety of cultural sites. From their experiences, teachers developed lesson plans and materials pertinent to their interests. This collection consists of these lesson plans and materials, divided up into the following categories: Environmental Issues, Daily Student Life, Compairing and Contrasting Cultural Values, Diversity in the Andes, Cultural Patrimony, and Andean Textiles".

Further more, PCs were used for creating and displaying open text books, such as the Community College Open Textbook Collaborative "This is a collection of open textbooks currently under consideration for review by the Community College Open Textbook Project (http://www.collegeopentextbooks.org) of the Community College Consortium for Open Educational Resources (http://oerconsortium.org)".

PCs were used for creating and displaying ePortfolios and ePortfolio standards. Examples: Institutional ePortfolio research; A series of white papers on ePortfolios written for Educause Learning Initiative and the EduTools ePortfolio Review Project - "In the Spring of 2006, EduTools and ePAC International undertook the review of seven ePortfolio products on the behalf of seven partner institutions or systems of institutions. In consultation with ePAC and the project partners, a set of 69 electronic portfolio features were identified and defined by Bruce Landon. Based on those features, reviews were conducted and completed in April 2006. According to the agreement with the partners, the feature set and reviews are now available for public use. Select the "Product List" link above to access the product reviews. http://eportfolio.edutools.info/static.jsp?pj=16\&page=HOME".

PCs were also used for displaying online courses. Examples: Western Civilization - History course "This course offers an introduction to the major themes of Western civilization, many of 
which have had a profound influence on American society and culture. The course will describe the development of Western civilization from its ancient origins in the Mediterranean, including Greece and Rome, to the end of the Cold War in the early 1990s"; or the online courses of the Open Course Library at Washington State - "These are free, online courses that are part of the Open Course Library at Washington State, a collection of shareable course materials created for faculty to use in their classes. As part of the Open Course Library this content is licensed under the Creative Commons Attribution License which means that you are free to reuse the course in its entirety, edit it and use your own modified version, or pick out only pieces which can be incorporated into your own course, as long as you credit the original author for their work. To access all materials for this course you may download either the ANGEL export file or the IMS Common Cartridge file. While the ANGEL file is specific to that system, the Common Cartridge file is compatible with many learning management systems. More information on Common Cartridge is available at http://www.imsglobal.org/cc/". In other cases support material for online courses were displayed.

PCs were associated with the websites of 420 courses and were used for publishing the course or contained resources related to the course subject matter. Additional usages included a PC as a space for teachers from diverse disciplines and a PC for creating and displaying Workshops.

\section{Discussion and Conclusion}

MERLOT is a free and open online community of resources designed primarily for faculty, staff and students of higher education from around the world to share their learning materials and pedagogy (Jorum, 2006; Reisman, 2009). Everyone (MERLOT members or non-members) can view and use PCs available in MERLOT (Ochoa \& Duval, 2009). Members can create a PC as well. All PC are shared with the community; they are completely online, and can be used at any time and any place. The PC can be customized easily and quickly for individual needs without requiring special technical knowledge, and is applicable for a variety of uses.

Learning object repositories are a shared, open and public space. However, the possibility and ability of personal expression in an open, global, public space is crucial. Alongside the many advantages inherent in sharing and integrating materials in a public space, PCs allow users to selfexpress themselves within the learning and creative process. Users construct, preserve and present knowledge in a way uniquely suited to their individual patterns of use. Creators of these learning processes can use materials developed by others and include them in their personal spaces within the repository. PCs enable the construction of a unique learning process in private spaces that suits the learner's needs, and therefore, increases user / member satisfaction. Furthermore the number of PCs for learning material has been demonstrated to be highly correlated with quality, since it is positively associated with good materials for every category of discipline, and the rating threshold in which it has presented significant difference (Cechinel et al. 2011). As PCs are known to be a good predictor of high ratings (García-Barriocanal, \& Sicilia, 2009), this is reflecting that items included in many PCs are more likely to have high ratings and to be recommended (Sicilia, et al., 2010).

The PC is a web base tool. For the user/ member there is no special equipment necessary other than access to the internet. For MERLOT, internal resources are invested to develop and build the PC platform. A PC is an online format for wider adoption in large scale. It is applicable in a variety of uses and can be used by ALL (members and non- members, faculties and students, k-12 teachers, librarians, content developers, etc.), all over the world, free of charge and with no need for special skills and tools. Consequently, the $\mathrm{PC}$ is a highly cost effective approach to supporting instruction and learning processes. 
In this paper the usage of PCs in the MERLOT repository has been discussed theoretically and empirically evaluated. The findings of this study will help us gain insight into the actual process of PC publication in the MERLOT repository, along with adaptation to other communities connected to MERLOT, such as the MAOR and Chile future repository. Understanding the process of creation and usage of the PC within learning object repositories will help the administrator of the repositories to design and plan the technological infrastructure needed to receive, store, and share the published PCs. Policy-makers can also use this analysis to evaluate the best approaches for encouraging contributors to publish their PCs.

\section{References}

Abelson, H. (2008). The creation of OpenCourseWare at MIT. Journal of Science Education and Technology, 17(2), 164-174.

Bonk, C. J. (2009). The world is open: How web technology is revolutionizing education. San Francisco, CA: Jossey-Bass, a Wiley imprint.

Butcher, N., \& Hoosen, S. (2012). Exploring the business case for open educational resources. Commonwealth of Learning, British Columbia: Vancouver.

Cechinel, C., Sanchez-Alonso, S., \& Garcia-Barriocanal, E. (2011). Statistical profiles of highly-rated learning objects. Computers \& Education, 57(1), 1255-1269.

Cohen, A., Shmueli, E., \& Nachmias, R. (2011). The usage of data repositories: The case of MAOR. Interdisciplinary Journal of E-Learning and Learning Objects (IJELLO), special series of Chais Conference 2011 best papers, 7, 323 - 338. Retrieved from http://www.ijello.org/Volume7/IJELLOv7p323338Cohen762.pdf

Dahl, O. J., \& Nygaard, K. (1966). SIMULA - An ALGOL based simulation language. Communications of the ACM, 9(9), 671-678.

De Liddo, A. (2010). From open content to open thinking. World Conference on Educational Multimedia, Hypermedia and Telecommunications (Ed-Media 2010), Canada.

The Directory of Open Access Repositories - OpenDOAR. (2011). Growth of the OpenDOAR DatabaseWorldwide. Retrieved August 15, 2011 from http://www.opendoar.org/find.php?format=charts

Downes, S. (2007). Models for sustainable open educational resources. Interdisciplinary Journal of Knowledge and Learning Objects, 3, 29-44. Retrieved from http://www.ijello.org/Volume3/IJKLOv3p029-044Downes.pdf

Friesen, N. (2009). Open educational resources: New possibilities for change and sustainability. The International Review of Research in Open and Distance Learning, 10 (5), 1-13.

García-Barriocanal, E. and Sicilia, M.A. (2009). Preliminary explorations on the statistical profiles of highly-rated learning objects. Proceedings of the Third Metadata and Semantics Research Conference (MTSR 2009), Springer Communications in Computer and Information Science 46, pp. 108-117.

Hilton J. L., Wiley, D., Stein, J., \& Johnson, A. (2010). The four 'R's of openness and ALMS analysis: Frameworks for open educational resources. Open Learning: The Journal of Open, Distance and eLearning, 25(1), 37-44.

Hilton, J. L., Wiley, D. (2011). Open access textbooks and financial sustainability: A case study on Flat World Knowledge. The International Review of Research in Open and Distance Learning, 12(5), 18 26.

Hilton, J. L., Lutz, N., \& Wiley, D. (2012). Examining the reuse of open textbooks. International Review of Research in Open and Distance Learning, 13 (2), 45-58.

Hylén, J. (2006). Open educational resources: Opportunities and challenges. Retrieved February 7, 2012 from http://www.oecd.org/dataoecd/5/47/37351085.pdf 
The JORUM Team. (2006). E-learning repository systems research watch. Project Document.

Malloy, T. E., \& Hanley, G. L. (2001). MERLOT: A faculty-focused Web site of educational resources. Behavior Research Methods, Instruments, \& Computers, 33(2), 274-276.

MERLOT. (2012). Multimedia educational resource for learning and on-line teaching website [On-line]. Available at http://www.merlot.org/

Monge, S., Ovelar, R., \& Azpeitia, I. (2008). Repository 2.0: Social dynamics to support community building in learning object repositories. Interdisciplinary Journal of E-Learning and Learning Object, 4, 191-204. Retrieved from http://www.ijello.org/Volume4/IJELLOv4p191-204Monge.pdf

Ochoa, X., \& Duval, E. (2009). Quantitative analysis of learning object repositories. IEEE Transactions on Learning Technologies, 2(3), 226-238.

Sicilia, M. A., García-Barriocanal, E., Sánchez-Alonso, S., \& Cechinel, C. (2010). Exploring user-based recommender results in large learning object repositories: the case of MERLOT. Procedia Computer Science 1, 2859-2864.

The Open University of Israel. (2012). Opening the treasures of the mind: Open access to textbooks and study materials. Retrieved February 7, 2012 from http://ocw.openu.ac.il/eng files/english.html

Qian, G. (2010). The Web as PLE: Perspective from educational technology and internet psychology. ICETC2010: Proceedings of the 2nd International Conference on Education Technology and Computer, pp.V1-262-V1-266.

Razavi, M. N., \& Iverson, L. (2006). A grounded theory of information sharing behavior in a personal learning space. CSCW '06: Proceedings of the 20th Anniversary Conference on Computer Supported Cooperative Work, pp. 459-468.

Reisman, S. (2009). Using learning objects to affect educational outcomes. Computer, 42(8), 102-104.

Taylor, J. C. (2007). Open courseware futures: Creating a parallel universe. E-Journal of Instructional science and technology, 10(1), 1-9.

World Forum of UNESCO Chairs. (2002). Proposal for launching the "Academics across Borders" initiative. Paris. Retrieved February 7, 2012 from

http://portal.unesco.org/education/en/file download.php/ba88fefb95a301b90e6395044552516baab do c 2002.pdf

Wiley, D. (2007). On the sustainability of open educational resource initiatives in higher education. Paper commissioned by the OECD's Centre for Educational Research and Innovation (CERI) for the project on Open Educational Resources. OECD 2007.

Wiley, D., Green, C., \& Soares, L. (2012). Dramatically bringing down the cost of education with OER: How open education resources unlock the door to free learning. Retrieved from http://www.educause.edu/library/resources/dramatically-bringing-down-cost-education-oer-howopeneducation-resources-unlock-door-free-learning 


\section{Biographies}

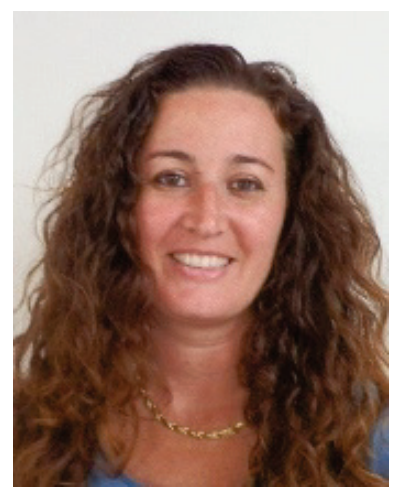

Anat Cohen is a researcher and a lecturer in Tel-Aviv University's School of Education. Her Ph.D. dissertation analyzed the costeffectiveness of Web-based Education, based on theoretical and computational models and empirical data using web-mining techniques. She participated in the IEA's Second International Technology in Education Study (SITES) and is currently a research and pedagogical coordinator of Virtual TAU - Web-Supported Academic Instruction in Tel-Aviv University. She has published over 40 research papers in leading peer-reviewed journals and conference proceedings. Her main research areas are: Cost-Effectiveness of Web-based Learning, Learning object repositories, Ubiquitous Learning, ICT implementation in Higher Education, Educational Data-Mining.

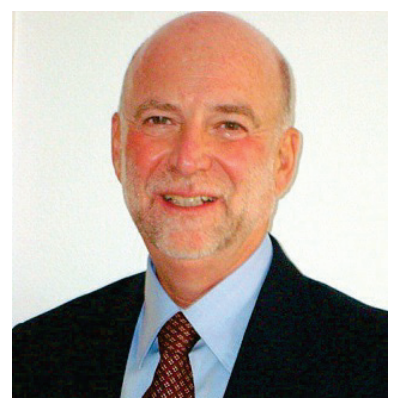

Dr. Sorel Reisman was 2011 President of the IEEE Computer Society, and is Managing Director of the international, higher education eLearning consortium, MERLOT.ORG at the California State University Office of the Chancellor, and Professor of Information Systems at California State University Fullerton. Reisman is a member of the IEEE Education Activities Board, the Publication Services and Products Board, and Editor-in-Chief of the IEEE Electronic Learning Products Library. As Computer Society Past President, Reisman chaired the Intersociety Cooperation Committee, responsible for the relationships with sister computer societies around the world. Dr. Reisman has held senior management positions at IBM (Canada and US), Toshiba (US), and EMI (UK). He is a Senior IEEE member, was Vice President of the Computer Society Publications Board, and Vice President of the Electronic Products and Services Board where he developed and initiated the Computer Society's eLearning and online books programs. He is currently a member of the IEEE Education Activities Board and liaison to the IEEE Technical Activities Board.

Dr. Reisman was editorial board member/columnist on IEEE Software, founding board member of IEEE Multimedia and IEEE ITPro, author of the column, The Ivory Tower, and reviewer for IEEE Transactions in Education. Reisman has presented/published more than 50 articles and the books Multimedia Computing: Preparing for the $21^{\text {st }}$ Century, and Electronic Learning Communities - Current Issues and Best Practices. Reisman received his electrical engineering degree, and MA and PhD in Computer Applications from the University of Toronto.

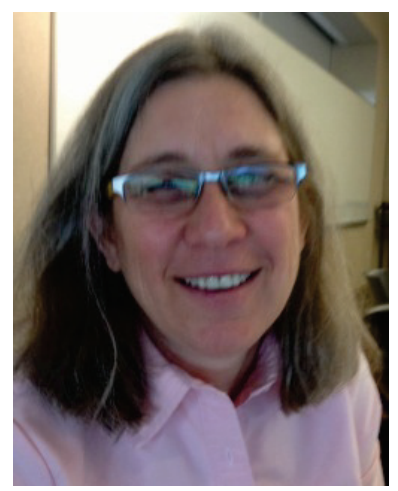

Barbra Bied Sperling is the Manager of Technical Development for MERLOT, the international, higher education eLearning consortium, MERLOT.ORG at the California State University Office of the Chancellor. Prior to that she was the Webmaster for the website almost since its inception 14 years ago. Barbra has held positions at California State University, Long Beach in the Center for Design and Accessibility and Ashton-Tate prior to working for MERLOT. Barbra has presented over 25 different workshops and seminars on MERLOT.org. 